\title{
Thermal Influence on Long-Distance Optical Measurement of Suspension Bridge Displacement
}

\author{
Luís Lages Martins • José Manuel Nunes Vicente Rebordão • \\ Álvaro Silva Ribeiro
}

Received: 31 July 2013/ Accepted: 21 April 2014

(1) Springer Science+Business Media New York 2014

\begin{abstract}
This paper discusses the thermal influence on long-distance and noncontact measurement of suspension bridge three-dimensional displacement by the use of an optical system composed of a digital camera, infrared active targets, and computational support. In this type of measurement method, the optical propagation path of light through the air can range from $250 \mathrm{~m}$ up to $750 \mathrm{~m}$, making its measurement accuracy strongly dependent on atmospheric refraction and turbulence, phenomena that are linked to the vertical temperature gradient between the camera and targets. In addition, the adopted measurement geometrical configuration can lead to a height difference between these two elements (camera and targets) above $50 \mathrm{~m}$. The paper describes the experimental setup and procedure followed for the determination of local temperature vertical gradients in the 25th of April Bridge in Lisbon (Portugal), where an optical measurement system was applied. The obtained thermal measurements are presented and applied in the evaluation of the systematic refraction vertical deviation, based on appropriate mathematical models mentioned in the paper, and for the identification of stable or unstable observation thermal conditions related to turbulence.
\end{abstract}

Keywords Displacement - Optical system $\cdot$ Suspension bridge $\cdot$ Temperature

L. Lages Martins (凶) · Á. Silva Ribeiro

Scientific Instrumentation Center, National Laboratory for Civil Engineering, Lisbon. Portugal e-mail: Ifmartins@lnec.pt

Á. Silva Ribeiro

e-mail: asribeiro@Inec.pt

J. M. Nunes Vicente Rebordāo

Laboratory of Optics, Lasers and Systems, Faculty of Sciences, University of Lisbon. Lisbon, Portugal e-mail: jmrebordao@fc.ul.pt 